\title{
Procedimiento para aplicar la cláusula general antiabuso*
}

\section{Rules for application of General Anti-Avoidance Rule}

\section{Pablo Mauricio Sarmiento Mancipe ${ }^{1}$}

\section{Resumen}

Por décadas Colombia ha tenido una gran preocupación por el riesgo de la elusión fiscal, por esta razón el Congreso colombiano introdujo en su estatuto fiscal la Norma General Antielusión, mediante la Ley 1607 de 2012. Basándose en la Ley de Procedimiento Administrativo y Procesos Administrativos y en la legislación tributaria, este trabajo propone un breve análisis para comprender la normatividad de la GAAR e identificar las diferentes etapas del procedimiento administrativo que permite su aplicación, pues la ley no reguló este tema. Sin embargo, para lograr este objetivo fue necesario investigar varias situaciones de naturaleza sustantiva de este instrumento jurídico, como su naturaleza jurídica, estudiar su finalidad en el sistema tributario, así como investigar el significado del concepto "propósito comercial", porque es uno de los requisitos que deben ser interpretados, con el fin de detectar y corregir las operaciones que constituyen la elusión fiscal.
Palabras clave: reglas generales antiabuso, normas para la aplicación de las normas generales antiabuso, propósito de negocio, formas legales inapropiadas o inadecuadas, evasión de impuestos, ahorros fiscales.

\begin{abstract}
For decades Colombia has had a major concern over the risk of tax avoidance, for that reason the Colombian Congress introduced the General Anti-Avoidance Rule in its tax statute, through law 1607 of 2012. Based on the Administrative Procedure and Administrative Process Law and tax law, this paper proposes a brief analysis for understanding the GAAR regulation and identify the different steps of the administrative procedure that allows its application, because the law did not regulate this topic. However to achieve this goal, it was necessary to research several conditions of substantive nature of legal tool, such as its legal nature, study its purpose in the tax system, as well as investigate the meaning of the concept
\end{abstract}


"business purpose", because it is one of the requirements that must be interpreted, in order to detect and correct the transactions that constituting tax avoidance.

Key words: the general anti-avoidance rule, GAAR, rules for application of general antiavoidance rule, business purpose, inappropriate or unusual legal forms, tax avoidance, tax savings.

\section{Sumario}

Introducción. I. Naturaleza Juridica. II. Responsabilidad Jurídica. III. Configuración. IV. Finalidad. V. Corrección. VI. Elementos. VII. Aplicación. Conclusiones. Referencias.

\section{Tabla de abreviaturas}

CGA Cláusula General Antiabuso

E.T. Estatuto Tributario

C.N. Constitución Nacional

\section{Introducción}

Si bien la tipificación de la cláusula generl antiabuso - en adelante CGA - mediante la Ley 1607 de 2012, no fue el mejor comienzo para este mecanismo, en cuanto a su aplicación efectiva, se debe resaltar que la importancia de su debut radica, no solo en irradiar efectos disuasorios a los obligados tributarios, sino también en reconocerle un espacio como remedio jurídico para combatir la elusión.

Vale la pena destacar que este "lugar" no lo conquista la CGA, por la insuficiencia de los tradicionales métodos aplicativos del derecho ¡ni mucho menos $;$, sino por la incomprensión generalizada del verdadero radio de acción que poseen estos mecanismos preexistentes, para conjurar ciertos comportamientos elusivos.

Esto se debe a la falta de dimensionamiento del problema que por décadas se tuvo en frente, y que muchas veces propició la jurisprudencia y la autoridad tributaria ${ }^{2}$ mediante confusos argumentos y errados conceptos alrededor de este fenómeno, y que hoy abonan el terreno para darle una connotación un poco mesiánica a este nuevo régimen.

Dejando de lado esta perspectiva, la necesidad de incorporar la CGA en la legislación reside, más bien, en complementar el arsenal de herramientas dirigidas a luchar contra ciertos actos elusivos, lo que compagina con el reclamo que venían haciendo varios sectores de la doctrina patria, como lo hizo la profesora Hoyos (2006), quien opinaba que:

El principio general del fraude a la ley no puede ser aplicado en materia tributaria, porque el mismo no tiene una consagración expresa en nuestro ordenamiento y porque la elaboración jurisprudencial que ha habido en torno al mismo en otras ramas del derecho, a nuestro parecer, no puede ser extendida a materias tributarias.

En igual sentido, cuando aún se adolecía de la CGA en la ley fiscal, Muñoz y Zornoza (p. 258) señalaron que la corrección de la elusión residía en la integración del ordenamiento a través de la CGA tras el fracaso de la interpretación de las normas, lo que, a su vez, también permitiría superar la marcada reticencia que impedía reconocer a la inte-

${ }^{2}$ Concepto DIAN 51977 del 2 de agosto de 2005. 
gración analógica como mecanismo viable de aplicación del derecho tributario.

Este preámbulo permite vislumbrar la existencia de una medida extraordinaria, no solo porque era requerido para enfrentar la elusión, cuando se superan los tradicionales mecanismos de interpretación de las normas, como la calificación de los actos o negocios a partir de la interpretación finalista de la ley tributaria, sino también por la particular estructuración sustantiva y procesal que a estas normas le dispensó el legislador tributario.

Merece la pena mencionar que, en esa primera oportunidad, el Congreso fue muy celoso al dictar este régimen y, por ello, incorporó salvaguardas e hipótesis que condicionaron la aplicación de la CGA, cuyo pronunciamiento depende de un requerimiento conminatorio distinto a la oportunidad para suministrar las pruebas y desvirtuar el abuso, asimismo, asignó facultades al ente fiscal con el fin de corregir la elusión fiscal una vez así fuese declarada.

Resulta notorio el enfoque cauteloso del legislador, al designar en un órgano ajeno a la administración tributaria la competencia de decisión - comisión consultiva en España-, para contribuir con la unificación de criterios y, superar situaciones de arbitrariedad e inseguridad jurídica que pudieran derivar de su aplicación, durante el procedimiento de gestión tributaria.

Tampoco puede desconocerse que la intervención del órgano legislativo resultó desafortunada, pues no fue integral, sino puntual y aislada sobre el texto normativo, lo que generó una redacción confusa y un procedimiento fragmentario y complejo que, por un lado, configuró concretas situaciones que dificultan su ejecución dinámica y, por el otro, la proliferación de múltiples interpretaciones, que coadyuvaron a gestar en el imaginario colectivo un consenso que coincide con las pocas posibilidades respecto a su aplicación.

Al margen de este sombrío y desesperanzador panorama, pero guiados por la metodología jurídica, y apegados al estudio de la normatividad administrativa, tributaria, así como del iter legislativo y la estructuración que finalmente tuvo esta iniciativa en el Congreso, nos dimos a la tarea de desarrollar como objetivo principal, el conjunto de actos que de forma lógica y precisa condujeran a la declaración definitiva de una conducta de abuso tributario.

El faro que permite arribar a este puerto, se enfoca tanto en el estudio de la institución jurídica que representa la CGA, como en la investigación de situaciones de índole sustantiva y procesal que gravitan alrededor de esta regla - que genera o no proporciona su positivización-; compilado con los principios, derechos y garantías del derecho adjetivo de raigambre constitucional, que esclarecen la aplicación de esta herramienta.

Razón tiene García citado por (Piza y Castro, 2010) cuando indica que "el procedimiento tributario no es sino el último eslabón de un proceso que tiene como finalidad traducir a la práctica el sistema tributario justo que la Constitución preconiza" (p. 509), lo que demuestra que abordar la aplicación de cualquier fenómeno tributario sin el estudio conjunto del derecho procedimental y sustancial tributario resulta impensable.

\section{Naturaleza jurídica}

El cumplimiento de este medular cometido exigió, en primer lugar, establecer si esta normatividad era de carácter sancionatorio o no, pues en caso afirmativo el desarrollo del procedimiento debía estructurarse a partir de 
la regla supletiva del art. 638 del Estatuto Tributario, que regula de manera general el procedimiento que dispone el ente tributario para imponer sanciones, cuando respecto de estas no se haya consagrado un procedimiento específico.

Además, cuando se realiza un acercamiento desprevenido a los textos normativos de la CGA contenidos en los art. 869 al 869-2 de la ley fiscal, se tiene la "impresión diagnóstica", - como se utiliza en el argot médico-, que estamos en presencia de un precepto sancionatorio, máxime cuando de ese linaje son la mayoría de categorías jurídicas que predominan en el Libro $\mathrm{V}$ del Estatuto Tributario, y que también incluye la normativa en estudio.

i. Al discernir la naturaleza jurídica de la CGA desde una óptica material, se concluye que no es una institución autónoma, pues su aplicación depende de la integración con otras normas tributarias, que le permiten ejecutar un procedimiento de corrección de las conductas de abuso tributario para identificar el precepto - previsto en la ley fiscal - que gobierna una operación, cuyos hechos económicos - exteriorizados - han sido distorsionados mediante maniobras fraudulentas, para que coincida con un presupuesto normativo de baja imposición.

Ello denota que, en éste procedimiento lógico no se supera una laguna jurídica, a diferencia de la integración analógica - método que la doctrina relaciona con la aplicación de la CGA - , en la que hay dos casos semejantes, y uno de ellos no ha sido regulado por el legislador. Sin embargo, estos mecanismos sí tienen en común que valoran las situaciones jurídicas que solucionan, buscando razones de identidad que permita la atribución de las consecuencias jurídicas que la norma aplicable al caso determine.
Este razonamiento es el que permite a la CGA corregir los esquemas contractuales adoptados por las partes, cuando luego de comparar el hecho económico realizado y la forma adecuada, se advierte que el resultado económico logrado es similar - no superior (habría razón mercantil) ni inferior (no habría fraude) - , con el supuesto del hecho tributario que el administrador dejó de aplicar, y que resulta más gravoso.

$\mathrm{Si}$, adicionalmente, la operación adolece de propósito comercial y solo se sustenta en la consecución de un ahorro fiscal, se configura una conducta de abuso tributario, lo que desvirtúa la presunción de que su ropaje jurídico es el adecuado, faculta a la autoridad tributaria a recalificar el negocio y a aplicar la norma contemplada en la ley fiscal - no querida debido a la actuación de quien actuó en fraude-, al hecho económico elusivo, como si este revistiese desde un principio la figura jurídica adecuada.

La ejecución de este procedimiento con afinidad analógica no crea tributos ni determina sus elementos esenciales - no vulnera el principio de reserva de ley - , pues se trata de actividad aplicativa del derecho que, apoyada en la finalidad de la ley fiscal, hace exigible el tributo, tal como debió nacer en el supuesto de que se hubiere acudido a la configuración jurídica correspondiente a la operación económica, es decir, que procede la neutralización de sus alcances, recalificándola a efectos tributarios (Hensel, 2000, pp. 227-278).

Aunque algunos autores señalan que los negocios elusivos son ilícitos por los artificios que incorpora, otros no aceptan que se les califique de antijurídicos, pues afirman que dejar de aplicar una ley fiscal por otra, que concede ventajas fiscales y consigue fines económicos equivalentes, no constitu- 
ye infracción directa, ya que no hay norma que prohíba obtener estos resultados por vías distintas a las previstas por el legislador, además las operaciones empleadas son válidas y no se ocultan al ente fiscal (CahnSpeyer Wells, 2016, p. 495).

La no realización del hecho imponible y la inclusión de conceptos indeterminados en su tipificación - generaría arbitrariedad-, son raciocinios que abogan para que esta regla no sea sancionatoria, sin embargo, es la dependencia para desplegar sus efectos jurídicos, pues no provienen directamente de la CGA, sino de la actuación que reconstruye a posteriori el hecho imponible - que resulta ficticio - , el argumento que defiende no asignar el carácter sancionador a esta norma, en atención al principio de tipicidad y legalidad que rigen el derecho punitivo.

ii. El análisis no se limitó a estudiar la institución como la reconoce la doctrina y la jurisprudencia comparada, sino que se abordó también desde una perspectiva formal, es decir, desde la propia redacción de la norma nacional, pues nada obsta para que la ley estructure o califique a la CGA como una sanción, por lo que evaluamos unas características que permiten auscultar la existencia de una categoría jurídica de la que derivan consecuencias especiales.

Bajo el test expuesto por (Vargas, 2014), se verificó que el ejercicio de la CGA le compete a una autoridad administrativa, asimismo, tiene efectos negativos o desfavorables - recaracterizar la operación-, además es consecuencia de la realización de una conducta antijurídica; empero, se dedujo que no tiene una finalidad represiva o de castigo - pues no genera un deber jurídico adicional, solo restablece la legalidad-, y tampoco cumple el principio de tipicidad (lex certa).
Esto se debe a que no contiene un texto normativo determinado ni determinable, del cual pueda advertirse la presencia de una sanción en sentido estricto y, también, porque si bien irradia consecuencias jurídicas, estas no son de tipo sancionatorio, pues solo se dirigen a enderezar el debido cumplimiento de la obligación tributaria principal incorporada en la ley, por lo que se concluyó que la CGA no está gobernada por la potestad sancionatoria ni su aplicación debe observar el procedimiento sancionatorio especial que incorpora el E.T.

Todo ello, sin perjuicio, claro está, que durante el ejercicio de las facultades de desconocimiento de los efectos de la conducta abusiva - recaracterización o reconfiguración de la operación - , se ponga en evidencia la defectuosa observancia de otras obligaciones diferentes a la principal - deberes formales, obligaciones tributarias accesorias - , que pueden llegar a configurar hechos sancionables por otras normas del Estatuto Tributario.

\section{Responsabilidad jurídica}

Descartado que la CGA es un tipo sancionatorio, la siguiente actividad emprendida nos permitió colegir que la potestad que disciplina la aplicación de esta norma, es la potestad ejecutiva o de gestión, ya que a la administración le corresponde ejecutar un deber jurídico definido en el ordenamiento, en este caso en el art. 95 numeral 9 de la Constitución Nacional.

Haciendo un paréntesis, resulta importante resaltar que el deber de "contribuir a los gastos públicos" constituye un bien jurídico merecedor de protección por el derecho punitivo del Estado, por lo que su vulneración supondría un sometimiento íntegro de los 
principios, garantías y dogmática que obedece el derecho penal al derecho administrativo sancionador.

Sin embargo, ha hecho carrera en la doctrina constitucional ${ }^{3}$ que el desconocimiento del derecho administrativo sancionador -al que pertenecen las infracciones y sanciones tributarias -, constituye la simple desobediencia de un mandato legal, con el pretexto de que este marco jurídico tutela solo la organización y orden interno de la administración, es decir, custodian un interés administrativo, como comenta (Zornosa y Muñoz, 2010).

Por el contrario, estos expertos fiscalistas recalcan que la finalidad del régimen de infracciones y sanciones tributarias, no busca meros intereses administrativos de "autoprotección", pues estos mecanismos persiguen el cumplimiento de obligaciones y deberes tributarios esenciales para asegurar los fines sociales del Estado, en concordancia con el art. 209 de la C.N. que ordena "la función administrativa está al servicio de los intereses generales".

El efecto de esa línea jurisprudencial, se evidencia al endilgar responsabilidad en materia tributaria, pues no es indispensable valorar el componente subjetivo de la conducta del infractor a título de dolo o culpa, sino únicamente cotejar la concurrencia objetiva de una conducta que desconozca un determinado mandato, como predomina en las decisiones del Consejo de Estado, a pesar de que en la C.N. proscribe la responsabilidad objetiva.

En relación con la CGA comenta (Ruiz y Seitz, 2004) que la intencionalidad subjeti- va de evitar el impuesto está presente en los supuestos de fraude, pero no es elemento constitutivo de esta cláusula antifraude, por lo que se reconduce a la verificación de los elementos objetivos previstos en la normatividad, siendo innecesario revisar la voluntad del sujeto infractor o si era consciente de que sus operaciones eran contrarias a derecho.

Así las cosas, al momento de verificar la ocurrencia de este tipo antielusivo, tampoco se considerarán formas de exclusión de la responsabilidad - distintas a la fuerza mayor y caso fortuito-, sino la mera realización de la conducta del agente, toda vez que el reproche se centrará en el perjuicio económico ocasionado a la hacienda pública o en el resultado de las acciones constitutivas de la infracción (Zornosa y Muñoz, 2010).

Ahora bien, cerrando el paréntesis y retomando lo referente a la potestad ejecutiva o de gestión aplicable en sede de la CGA, cabe anotar que esta otorga facultades a la administración tributaria en la etapa de fiscalización, no solo para investigar y comprobar aquellas desviaciones que impidieron la debida satisfacción de la legislación tributaria, sino también para imponer el remedio jurídico que restablezca el interés lesionado.

En este caso, el decisum de esta medida, se dirige a reparar la legalidad alterada por el obligado tributario mediante el desconocimiento de la conducta abusiva y, a asegurar los derechos de contenido económico que le pertenecen al Estado, a partir de la reconfiguración de la actuación y liquidación de la obligación tributaria sustancial que corresponda y, de este modo, suplir la inob- 
servancia del infractor y resarcir el perjuicio ocasionado.

\section{Configuración}

Antes de abordar el objetivo de la CGA, es preciso ahondar en la causa eficiente o causa fuente, es decir, en el hecho que genera la aplicación tanto del régimen general antiabuso como de las herramientas aplicativas del derecho, y para ello es necesario estudiar las numerosas actuaciones que generan las conductas elusivas.

La teoría del silogismo jurídico nos enseña: que el derecho aplicable a un caso concreto, se desarrolla mediante la subsunción de unos hechos de la realidad, en los supuestos de hecho de una norma jurídica, lo que se conoce como calificación y que, dentro de dicha estructura lógica, este ejercicio corresponde a la conformación de la premisa menor.

Comentan Muñoz y Zornoza (p. 254), que el proceso de subsunción del caso de la realidad - en todas las ramas del derecho-, no es una labor sencilla, ya que debe entremezclarse con valoraciones, que en ocasiones la ley facilita mediante notas distintivas del supuesto de hecho, pero en otras oportunidades no aporta ninguna referencia normativa; además el derecho tributario posee circunstancias especiales que dificultan esta valoración.

Estos inconvenientes provienen: a) del diseño de la propia norma tributaria, ya que el Congreso cuando ejerce su poder tributario selecciona situaciones de la realidad económica, reveladores de riqueza, tales como: comprar, vender, prestar, invertir, donar, etc., - hechos con sustrato o significado económico- de los que se infiere capacidad económica o aptas para perseguir otras finalidades no fiscales - materia imponible u objeto del tributo- .

Ello le permite, luego, hacer una formulación o descripción general y abstracta de acontecimientos, actos o negocios jurídicos, situación jurídica de una persona o de sus bienes, actividad de un sujeto, que conformarán el elemento material del presupuesto fáctico, empleando los términos y conceptos provenientes de las ciencias económicas o las figuras jurídicas reconocidas en el derecho privado.

Cuando estas conductas junto con otros aspectos - espacial, temporal-, que permiten matizar su alcance, se normativizan, es decir, se elevan a la categoría de disposición legal por obra del legislador, la hipótesis de incidencia se denomina hecho generador o imponible, y de paso aquella capacidad económica se transforma en capacidad contributiva, por lo que es susceptible de ser gravada, siendo estos efectos tributarios "en teoría" indisponibles por la configuración jurídica que los particulares proporcionen a sus actos o negocios.

Otra secuela de esta conversión, es que todos los aspectos de los supuestos fácticos adquieren naturaleza jurídica, por ende, de su realización se producen consecuencias jurídicas, como lo es el nacimiento de la obligación tributaria sustancial, asimismo cualquier oscuridad que se derive de su ocurrencia, no debe trasladarse a campos extrajurídicos sino jurídicos, con independencia de que el legislador utilice conceptos de las ciencias económicas o figuras procedentes del derecho privado para su configuración (Marín, 2010, p. 315).

La posibilidad que tienen los obligados tributarios de apoyarse en la autonomía de la voluntad (facultad para disponer con efecto vinculante de los intereses y derechos de los 
que son titulares y por ende crear derechos y obligaciones $)^{4}$, para satisfacer sus intereses y necesidades, no constituye ningún derecho subjetivo que permita "alterar la forma jurídica correspondiente a una determinada operación económica para que se tribute menos" (Ruiz y Seitz, 2004, p. 10).

En este punto, es oportuno resaltar que las conductas sujetas a tributación no se realizan únicamente desde el punto de vista de la forma jurídica empleada, sino también desde la perspectiva del sustrato económico o manifestación de capacidad económica que subyace en aquella y que da lugar a la imposición, según D. Birk, citado por (Ruiz y Seitz, 2004, p. 10).

Estos factores, aunado al interés de los obligados tributarios de desconocer la capacidad económica que posee el negocio o actividad, y amparados en una exagerada interpretación literal de la ley tributaria desligada de su finalidad-, crea un clima favorable para que se abuse de la libertad de formas del derecho privado, pues se adoptan esquemas o configuraciones jurídicas que impiden que se conforme la premisa menor, evitando así la realización del supuesto de hecho tributario.

Mediante este tipo de actuaciones se desconoce el espíritu de la norma, pues no resultan conformes con la ratio establecida por el legislador, lo que equivale al abuso de las formas jurídicas $-\mathrm{y}$ eso no es otra cosa - que el fraude a la ley tributaria-, ya que se materializan a través del uso o implementación de negocios válidos y lícitos, para escapar o debilitar los efectos de las leyes fiscales, constituyendo este proceder una infracción indirecta de las normas tributarias.
Estas reprochables conductas son especies elusivas - por definición serán abusivas-, y si bien se amparan en la literalidad de las normas, son incompatibles con el derecho tributario considerado en su conjunto, ya que conculcan el principio de capacidad contributiva, pues distorsionan el mandato que grava de igual manera a quienes tienen la misma capacidad de pago (equidad horizontal $)^{5}$, más no quebrantan directamente una norma jurídica específica.

De la configuración de estos tipos elusivos, también se deduce una tensión entre el principio de capacidad económica del derecho tributario $v s$. la libertad de formas jurídicas del derecho privado, y pese a no tener solución a la luz de la unidad del derecho, sí nos permite visualizar la siguiente arista: si en la interpretación de la norma fiscal, el criterio empleado para calificar los casos de la realidad atribuye el valor que poseen las figuras jurídicas en el derecho privado, se facilita la incubación de conductas de fraude tributario.

Por ello, para resolver este tipo de fraude - que no difiere sustancialmente del fraude del derecho común - , no se requiere averiguar la naturaleza del acto jurídico, sino realizar un acercamiento teleológico a la norma tributaria para determinar la finalidad que en este compendio cumple la forma jurídica, porque lo que interesa al derecho tributario no son los esquemas contractuales, sino lo que los administrados consiguen a través de ellas (Ruiz y Seitz, 2004, pp. 14-17-18).

Para identificar o verificar un supuesto de fraude a la ley tributaria, se deben considerar principalmente los siguientes elementos: a) el uso de una forma jurídica que si bien 
alcanza fines económicos queridos en el derecho privado, resulta inadecuada, porque realiza una manifestación de capacidad económica, u otro fin definido por la ley fiscal que resulta conculcado, b) la implementación de esta transacción tenga el único propósito de reducir la carga tributaria, c) que carezca de un motivo económico válido que justifique la operación.

\section{Finalidad}

El anterior recorrido argumentativo nos permite arribar a buen puerto, en la tarea de dilucidar el objetivo principal que persigue la CGA, el cual es determinar si la finalidad de las normas tributarias ha sido vulnerada, pues dicho propósito, es el que aporta significado y orden a los términos legales definidos por el legislador tributario.

Respecto a la finalidad de las normas fiscales, debemos indicar que el espíritu que las inspira, no es la mera recaudación, sino la capacidad contributiva demostrada en sus dos dimensiones, positiva y negativa (cuando exista o no), lo que legitima el deber de contribuir y sirve de medida de la imposición (González, 1997).

Esa capacidad contributiva se irriga en el sistema tributario no en forma genérica, sino de manera específica, con el fin de edificar la razón de ser de cada tributo - v.gr. impuestos ambientales, a las bebidas azucaradas, etc. $-\mathrm{y}$ "consiste en señalar, bajo una formulación abstracta, supuestos de hecho económicos de los que se infiere una capacidad contributiva" (Muñoz y Zornoza, p. 260).

La CGA aparte de resguardar la regla de justicia tributaria, consistente en que la car- ga tributaria debe consultar la capacidad económica de los sujetos gravados ${ }^{6}$, expone (Marín, 2009) que este procedimiento correctivo cumple una finalidad adicional y es "delimitar los comportamientos elusivos de la planeación fiscal".

Este deslinde resulta ideal, ante la ausencia de definición legal de estas estrategias, pues ambas, aunque se adecuan formalmente al marco jurídico, luego de aplicar los elementos de la CGA, es posible distinguir aquellas conductas que comportan una afrenta al plexo normativo tributario (elusión), de las que lo acatan en toda su magnitud (planeación fiscal).

\section{Corrección}

1. Con el fin de reencauzar aquellas transacciones abusivas en materia tributaria y aplicar las consecuencias jurídicas que les depara la ley fiscal, podemos acudir, en primer lugar, a la recalificación de los hechos e interpretación de las normas, y así dilucidar el hecho económico que realmente se realizó, apoyados en los mecanismos hermenéuticos civiles.

Para corregir estos fraudes a la ley tributaria, no se debe atener a la forma externa o denominación de los actos realizados, sino evaluar la verdadera naturaleza jurídica o las relaciones económicas que efectivamente comprenden para clasificarlas en los presupuestos de hecho previstos en la norma tributaria, lo que soluciona los casos de elusión "intentada".

Veamos el siguiente ejemplo de una donación en cadena, que se soluciona reclasificando los hechos, como lo expone Ruiz y Seitz (2004),

${ }^{6}$ Sentencia C-252 de 1997. 
Un padre dona a su hija una cantidad de dinero. Otra cantidad adicional la dona a su mujer, con la condición de que posteriormente sea también donada a la hija. De acuerdo con el Impuesto sobre Donaciones alemán, por cada donación entre determinados familiares hay una cantidad exenta, que coincide con la donada a la hija. Si hubiera realizado una sola donación, sólo una parte habría estado exenta. Al realizar la donación en dos pasos, se consigue la exención total de la cantidad donada. El BFH entendió que se trataba de una única donación (p. 25).

Cabe destacar el papel prevalente de la interpretación teleológica, para desentrañar los mandatos de la norma tributaria aplicable, pues esta herramienta guiada por la finalidad que persigue el derecho tributario, permite dilucidar el significado de los textos normativos más allá de sus términos formales y aparentes, salvo que la propia ley fiscal los hubiese definido.

No sobra indicar que el derecho anglosajón ha sido pionero en desarrollar doctrinas (sustancia sobre la forma, operaciones complejas, etc.), que han inspirado el derecho tributario comparado, las cuales se dirigen a analizar si la realidad económica de una operación, corresponde a la calificación jurídica que el contribuyente asigna a sus actuaciones.

2. Cuando se implementan esquemas complejos y sofisticados, conformados por actos sucesivos e independientes, aparece la elusión "realizada", pues estos andamiajes negociables superan los mecanismos aplicativos del derecho - la calificación de los hechos e interpretación finalista-, impidiendo que se formule la premisa menor.

Para corregir estas operaciones de abuso tributario, se debe acudir a los efectos jurí- dicos que provee la CGA: aplicar la norma tributaria defraudada que somete a imposición dicha realidad económica o materia imponible y así desmontar esos negocios que se amparan en la norma tributaria de cobertura - que configura el fraude-, siempre que concurran sus elementos constitutivos (provecho tributario, formas artificiosas y ausencia de propósito comercial).

Tanto la CGA como las doctrinas o técnicas del Common Law (sustancia económica, business purpose) coinciden en "negar protección jurídica a aquellos actos o negocios realizados sin un propósito negocial - que es el elemento clave para que pueda surgir la citada protección o reconocimiento-" como lo comenta (Ruiz y Seitz, 2004, p. 42).

\section{Elementos}

En Colombia los elementos constitutivos de la CGA, a título de umbrales de legitimidad o requisitos de antijuridicidad, que permiten calificar el abuso tributario son: a) la obtención de un provecho tributario, b) el uso de formas artificiosas, y c) ausencia de propósito comercial o de negocio legítimo o razonable.

El provecho tributario se refiere a la obtención de ventajas impositivas: eliminar, reducir o diferir el impuesto, aprovecharse de beneficios o exenciones, incrementar el saldo a favor o pérdidas fiscales, mientras que la figura jurídica artificiosa se deduce del contenido del negocio - según el comportamiento seguido por las partes - , ya que es indicativo de una capacidad económica distinta a la que refleja la forma exteriorizada ante los demás.

En cuanto a la demostración del tercer ingrediente - propósito comercial - , ha dicho (Ramírez, 2016,p. 115) que este con- 
figura una negación indefinida, por lo que a la administración solo le correspondería afirmar la ausencia de propósito comercial, para trasladar la carga de la prueba al administrado, a quien le correspondería probar su existencia.

Pero lo cierto, es que dicho elemento constitutivo de abuso comporta una negación definida de derecho, por ende, quien la alega, debe probar el hecho positivo contrario que implícitamente afirma, y que sirve de presupuesto de la norma, cuyo efecto jurídico persigue, - cuando se niega la capacidad, se asevera el estado de demencia -, como lo enseña el jurista Devis Echandía (2015, p. 197).

De acuerdo con la naturaleza inquisitiva del procedimiento tributario, que determina que la distribución de la carga de la prueba es objetiva (Whittingham, 2011, p. 25), concierne al ente fiscal verificar si el instrumento empleado - y demás elementospersigue un propósito económico adicional al ahorro fiscal, pues solo puede trasladarse al administrado, una vez desvirtúa la presunción de veracidad que goza la declaración tributaria (Estatuto Tributario, art. 746).

Respecto al significado de propósito comercial - desde la perspectiva del administrado-, este concepto se asimila con la finalidad que se pretende conseguir con el acto y a cuya consecución se dirigen sus actuaciones, lo que se identifica con la acepción "subjetiva" de la causa (Código Civil, art. 1524) que define Ospina y Ospina (2000) como "los móviles determinantes que inducen a las personas a la celebración de los actos jurídicos" y al que la Corte Suprema de Justicia ${ }^{7}$ agregó "han sido conocidos de las partes” (p. 277).
Estos móviles requieren trascender el fuero interno de los agentes, para convertirse en la razón práctica o causa de un determinado negocio, es decir, en el interés concreto y particular perseguido por las partes - lo que impulsa a contratar-, que recoge cada reglamento negocial - por ello resulta protegible por el ordenamiento jurídico-; pues como comenta Ferri (1968) la causa es la "expresión objetivada de las finalidades subjetivas que el autor o los autores del negocio intentan conseguir" (p. 372).

Como elemento estructural del acto jurídico que induce a los agentes a su celebración, la causa equivale al motivo determinante o el fin objetivo, inmediato o práctico del negocio o el interés que la operación se dirige a satisfacer, por lo que se contrapone a la mera intención o los motivos personales, secretos, íntimos y variables de las partes, no incorporados en la declaración de voluntad y que no están ni podran estar regulados por el derecho, solo sometidos a la moral individual.

Traslademos el caso emblemático Helvering vs. Gregory a Colombia, en el que se negó efectividad a una reorganización empresarial - escisión - con el argumento de que carecía de un objetivo comercial propio, porque su única finalidad era evitar el pago del impuesto, para explicar este razonamiento sobre el propósito comercial, para ello agreguemos hipotéticamente que la Sra. Gregory desarrolló algunos de los motivos que declaró en el proyecto de escisión (Ley 222, 1995, ordinal 1 del art. 4).

Este plan de reorganización debe tener relación con el negocio y comprender razones concretas para fragmentar la sociedad, entre otras "disminuir costos para lograr más

${ }^{7}$ Cas., 7 octubre 1938, “G.J.”, t. XLVII, núm. 1941, p. 252. 
eficiencia y aumentar los beneficios económicos, especializar los recursos operativos y técnicos para mejorar la productividad o separar funciones para diversificar riesgos, facilitar el mercadeo y el acceso al crédito", como ilustra (Narváez, 2008, p. 249).

$\mathrm{Si}$ algunas o todas estas actividades son llevadas al plano material, o tienen una relación lógica de causa efecto con la operación, independiente de los resultados que se logren - máxime cuando pueden ocurrir hechos imprevistos - , se estaría sustentando que la operación no es ficticia y que esta posee sustancia o propósito empresarial, a pesar que aquella llegase a generar coetáneamente un ahorro fiscal.

En contraste, el sentido de propósito comercial - desde la óptica del ente fiscal-, se asocia con el objeto específico de los actos jurídicos, es decir, su contenido jurídico, que consiste en los efectos que cada negocio está llamado a producir, bien sea en razón de las regulaciones voluntarias de los agentes o bien por ministerio de la ley que completa o suple la voluntad faltante - según la naturaleza del acto-, desde el momento en que las partes manifiestan su intención de obligarse recíprocamente y acuerdan los elementos esenciales, pudiendo descartar o limitar el alcance de las normas no imperativas (Ospina y Ospina, 2000, p. 237).

Estos fines específicos tanto voluntarios como legales, no solo individualizan el negocio realizado, sino también dimensionan y atribuyen el conjunto de las obligaciones y contraprestaciones que dimanan de cada acto jurídico - a cargo de las partes - lo que representa su función única y exclusiva, esto resulta decisivo porque trasciende al fuero externo de los agentes, en los que rige el orden jurídico.
En relación con las definiciones sobre objeto y causa, que proveen sentido al término propósito comercial, es preciso traer a colación la posición de (Hinestrosa, 1959) "decir que el negocio tiene como causa la finalidad determinante de realizar esa misma función o que la causa del negocio es esa misma función no es otra cosa que repetir la definición del negocio, incurrir [...] en una evidente tautología", pues hay sectores de la doctrina que equipara estas categorías jurídicas (Cubides, 2005) o confunde estos elementos estructurales del acto jurídico (Betti, 2010):

la causa es una entidad social que no se limita a atender los fines particulares de los contratantes porque permite tipificar un negocio y determinar su contenido, y en esa medida ofrece un control sobre lo que persiguen las partes cuando acuden a un tipo negocial; esa finalidad debe ajustarse a la función económico-social que caracteriza a ese determinado negocio. Adicionalmente, considera que esa función económico-social es lo que fundamenta el reconocimiento que el ordenamiento hace del negocio, en otras palabras, es lo que fundamenta la tutela jurídica.

Siguiendo el socorrido ejemplo de la doctrina, se constituye una sociedad para eludir el pago de la ganancia ocasional, uno de los socios aporta un inmueble y el otro dinero, al poco tiempo se disuelve y liquida la sociedad, luego se adjudican de forma cruzada las aportaciones iniciales; le corresponde a la administración apoyada en criterios objetivos desvirtuar el contrato de sociedad (no actividad comercial, proximidad fechas), así como resaltar la presencia del contrato 
de compraventa (equivalencia de los bienes cruzados).

$\mathrm{Al}$ respecto, hay que señalar que la función objetiva o típica que el ordenamiento le ha previsto al contrato de sociedad no es la transmisión patrimonial - aunque es uno de sus efectos - , sino la que establece el artículo 98 del Código de Comercio, lo que determina una notoria ausencia de propósito comercial o de negocio legítimo y razonable de esta operación.

Este abuso en la libertad de las formas jurídicas, configura un indicio, que hace necesario que se proceda a evaluar el resultado de la operación, es decir, la transmisión patrimonial que ocurrió realmente, para verificar si este fin económico perseguido por las partes coincide con la realización de uno de los supuestos de hecho indicativos de capacidad económica establecidos por el legislador tributario.

Cuando ello es así, se evidencia que la forma jurídica adoptada - contrato de sociedad - resulta un acto artificioso para la ley tributaria, pues mediante este negocio jurídico se altera, desfigura o modifica los efectos tributarios que debían recaer sobre el sujeto aportante del inmueble, quien debe soportar la carga tributaria de la operación con sustrato o sustancia económica - contrato de compraventa - y que además carece de propósito comercial.

\section{Aplicación}

Uno de los factores que más pesimismo ha generado en cuanto a la viabilidad de utilizar la CGA, ha sido la exigencia de que se verifiquen como mínimo tres supuestos de aplicación, a fin de que se active la potestad del cuerpo colegiado de requerir al administrado para que las desvirtúe o demuestre cualquiera de las salvaguardas o de manera subsidiaria conozca y decida la ocurrencia de una operación abusiva.

Toda vez que podríamos encontrarnos con escenarios en los que no concurran los supuestos del artículo 869-1 del E.T., o la administración tributaria no logre probar plenamente la ocurrencia de al menos tres de estas condiciones, así se constate la realización de los elementos constitutivos del abuso, no sería posible declarar el abuso en materia tributaria.

Otro de los recurrentes cuestionamientos a esta normativa es la conformación del comité por la dificultad de realizar sus sesiones, al margen de este acto material, podemos señalar que su competencia será la de conminar al obligado tributario, para que controvierta la ocurrencia de los supuestos de aplicación comentados, o que pruebe cualquiera de las circunstancias previstas en los numerales 1 y 2 del art. 869.

Esta atribución - conminatoria - estará a cargo del órgano colegiado, en los casos que participen personas jurídicas u otras entidades, así como personas naturales que sean propietarias o usufructuarias de un patrimonio líquido igual o superior a 192.000 UVT, para las demás personas, esta tarea se radica en la autoridad tributaria ${ }^{8}$.

La tarea de conminar debe abarcar además un requerimiento sobre la realización de la operación abusiva, para que el investigado se refiera a los elementos constitutivos de abuso - que hasta ese momento ha logrado demostrar la administración - , toda vez que

${ }^{8}$ Oficio DIAN 025473 del 2 de septiembre de 2015. 
ante una fallida defensa del procesado, que no le permita sustentar las salvaguardas, le corresponderá al comité, de manera subsidiaria, estudiar la existencia o no de abuso en la operación.

La segunda tarea del comité será resolver o pronunciarse mediante una decisión definitiva, acerca de la existencia concurrente o no de los elementos que estructuran una conducta de abuso tributario, la cual deberá desarrollar en todos los casos que se presente este comportamiento irregular, sin distinción patrimonial alguna.

Para declarar que una operación es abusiva se requerirá que la administración tributaria, no solo pruebe plenamente los supuestos de aplicación, sino también estructure y sustente un caso de abuso, con el fin de enrostrar la realización de una o varias operaciones que se adecuen a los elementos que constituyen esta reprochable conducta.

Con la notificación del escrito se traba una relación jurídica procesal, que le permite al obligado tributario oponerse a sus elementos de juicio, dando respuesta a los hechos jurídicamente relevantes que lo sustentan, presentando sus propios argumentos fácticos y jurídicos para desvirtuar la conducta abusiva que le endilga la administración, solicitar o aportar pruebas, así como controvertir las que se hubieren allegado en su contra.

La convocatoria que hace el comité, no constituye el hito que comienza este litigio como afirma (Ramírez, 2016, p. 125), pues el principio de eventualidad exige que todos los asuntos se planteen simultáneamente - la demostración de las salvaguardas y el pronunciamiento sobre el abuso-, además acudiendo al efecto útil de las normas, -inciso final art. 869-2 E.T. - no tendría sentido que el comité convocara en casos que no se advierta la posible comisión de abuso tributario, ni que la administración garantizara al administrado la oportunidad de desvirtuar la conducta abusiva, luego que el ente decisor conociera el asunto.

Este debate concluye con una declaratoria del comité para que se reconozca o niegue definitivamente la existencia de una operación abusiva, cuya consecuencia jurídica es que se ponga fin a un estado de incertidumbre sobre una relación jurídica tributaria existente, más no se persigue que este pronunciamiento constituya, modifique o extinga un nuevo estado jurídico - inexistente hasta ese momento-, como tampoco imponer una contraprestación adicional o determinada conducta al procesado.

Esa relación jurídica tributaria existe desde que se realizaron todos los elementos esenciales del hecho generador, así se emplee una forma jurídica inadecuada, pues en Colombia el deber de tributar nace con la realización del presupuesto normativo tributario ${ }^{9}$, y en nada afecta que luego de declarar el abuso tributario, ese ropaje jurídico ficticio se desconozca, se recalifique el negocio y el resultado económico logrado se subsuma en el supuesto de hecho eludido; lo que permite colegir que la providencia del comité, se identifica con las declaraciones de certeza o de carácter declarativo.

Como la decisión del Comité incorpora un pronunciamiento sobre la existencia de la obligación y el régimen tributario aplicable a un sujeto pasivo, esta constituye un acto administrativo definitivo - porque crea situaciones individuales o concretas - , por

${ }^{9}$ Sentencia C-231 de 2003. 
tanto, es susceptible de control administrativo, es decir, de que se solicite su aclaración, revocación o modificación, al igual que su impugnación judicial, previo agotamiento de la vía gubernativa.

Ha sentado la jurisprudencia administrativa $^{10}$, que cuando la expedición de la decisión carece de reglamentación concreta dentro de la compilación fiscal, no es dable conceder para su impugnación los recursos regulados por la Ley Tributaria, en consecuencia, para ejercer el derecho de defensa y contradicción, y el control administrativo de la decisión del comité sobre abuso, así como agotar la vía gubernativa, es el recurso de reposición, cuya oportunidad y presentación se advierte en el art. 76 del CPACA.

Toda vez que la aplicación de la CGA se realiza durante la etapa de fiscalización, las actividades de verificación y recaudo de la mayoría de medios probatorios cobra mayor relevancia y premura, debido a que el comité pronunciará decisión de fondo sobre el abuso tributario antes de que se expidan las liquidaciones oficiales de aforo o de revisión.

Es decir, que no se contará con las oportunidades regulares para allegar pruebas previstas en el art. 744 del E.T., tales como los requerimientos especiales y sus ampliaciones, lo que hace necesario que el interesado pueda controvertir las aportadas o practicadas antes de que se dicte la decisión de fondo, así como conocer antes de que se adopte el acto definitivo del comité, cualquier pronunciamiento que le deniegue el decreto de determinada prueba.

El traslapo que genera la decisión del comité, sobre las regulares oportunidades de aportar pruebas, hace reflexionar sobre la imperiosa necesidad de correr traslado puntual al investigado del material recaudado mediante algunos medios probatorios inspección tributaria, inspección contable, dictamen pericial y testimonio-, para que en ejercicio del principio de contradicción en forma independiente presente los descargos respectivos.

Sin embargo, cuando de estas diligencias se derive una actuación administrativa, esta ritualidad se reconduce en el escrito - inciso final del art. 869-2 del E.T. - que ordena requerir al administrado para que suministre las pruebas y argumentos que desvirtúen la existencia del abuso tributario, excepto para los testimonios que se realicen durante la visita, pues para estos resulta substancial que en su configuración se surtan con inmediatez, los principios de publicidad y contradicción de la prueba, so pena de ser excluidos como argumento probatorio.

La inspección tributaria y contable, tendrían prioridad para verificar el abuso tributario, sin embargo, la prueba de sus elementos constituyentes, encarna una gran dificultad probatoria, toda vez que los contribuyentes o responsables utilizan negocios serios y típicos para eludir el hecho generador más gravoso, lo que hace necesario contrarrestar estas desigualdades, mediante el apoyo de la prueba indiciaria, a pesar de su condición subsidiaria.

\section{Conclusiones}

No obstante, el sistema tributario estructura las imposiciones bajo principios de justicia, equidad e incluye mecanismos como las minoraciones estructurales y los beneficios

${ }^{10}$ Sentencia CE-17944 de 2010. 
tributarios, etc., los administrados construyen esquemas contractuales para desconocer la capacidad económica que poseen sus negocios, amparados en una interpretación exegética de las normas fiscales — desligada de su finalidad - evitando así la realización del supuesto de hecho tributario, lo que constituye el fraude a la ley tributaria.

Para hacer frente a esas reprochables conductas - la elusión "intentada" - , la autoridad tributaria ha contado con los métodos aplicativos de las normas en el derecho tributario - la calificación de los actos y la interpretación finalista de la ley tributaria-, sin embargo, las estructuras abusivas cada vez son más complejas y sofisticadas, conformadas por una sucesión de actos independientes - la elusión "realizada" - , lo que demanda el empleo de otras herramientas jurídicas como las clausulas antielusivas.

A pesar del desalentador panorama que nos legó la Ley 1607 de 2012, cuando tipificó la CGA, - pues estableció un procedimiento fragmentario y confuso, que configuró situaciones que dificultan su ejecución-, es posible concluir que el procedimiento está regulado y es viable su aplicación, salvo, claro está, las dificultades operativas de poner en funcionamiento el comité que se supedita a la expedición del reglamento.

Cabe destacar que en esta primera versión, el legislador exageró en la incorporación de salvaguardas y supuestos que restringen la aplicación de esta normativa a la presencia o ausencia de ciertas circunstancias (Estatuto Tributario, art. 869-1), al igual que la asignación de la competencia para decidir el abuso tributario a un órgano ajeno a la administración tributaria.

El procedimiento supletivo con que cuenta la administración para imponer sanciones (Estatuto Tributario, art. 638), no es aplica- ble a la CGA, toda vez que esta normatividad carece de carácter sancionatorio, ya que sus efectos jurídicos dependen de la integración con otras normas tributarias, que le permite reconstruir a posteriori el hecho imponible eludido; lo cual atentaría contra el principio de tipicidad y legalidad que rigen el derecho punitivo.

Desde la redacción de la CGA, se observa que esta no está gobernada por la potestad sancionatoria, sino por la potestad ejecutiva o de gestión - en atención al deber jurídico que prescribe el art. 95-9 de la Constitución-, pues pese a contener efectos negativos o desfavorables - recaracterizar la operación - , estos se dirigen a enderezar el debido cumplimiento de la obligación tributaria principal incorporada en la ley, es decir, adolece de una finalidad represiva o de castigo - pues no genera un deber jurídico adicional, solo restablece la legalidad - .

El objetivo del procedimiento de corrección de las conductas de abuso tributario la CGA - , es determinar la finalidad de las normas tributarias aplicable, es decir, si se ha desentrañado correctamente el significado de sus textos normativos, más allá de sus términos formales y aparentes, toda vez que si prevalece el valor que poseen las formas jurídicas en el derecho privado, se facilita el fraude a la ley tributaria; lo que simultáneamente lleva a delimitar las conductas constitutivas de elusión y de planeación fiscal.

Una vez se detecta que un hecho económico realizado posee un sustrato económico, que está gravado por un supuesto de hecho tributario con mayor imposición, y que en dicha operación concurren los elementos constitutivos de abuso tributario (provecho tributario, forma artificiosa y ausencia de propósito comercial), se procede a su corrección, recalificando los negocios ampa- 
rados por la norma tributaria de cobertura, mediante la aplicación de la norma tributaria defraudada - que el administrado dejó de aplicar-, y así someter a tributación dicha realidad económica, como si revistiese desde un principio la forma jurídica adecuada.

El propósito comercial es una negación definida de derecho, y desde la visión del administrado, se identifica con la causa que se declara en los actos jurídicos, es decir, con el interés concreto y particular que impulsa a las partes a contratar - se contrapone a los motivos personales, secretos, íntimos y variables-; y desde la óptica del ente fiscal, se asocia con el objeto de los actos jurídicos, o sea con los efectos específicos que cada negocio está llamado a producir, bien sea en razón de las regulaciones voluntarias de los agentes o bien por ministerio de la ley.

La declaratoria del comité para que se reconozca o niegue definitivamente la existencia de una operación abusiva, es una declaración de carácter declarativo, que busca poner fin a un estado de incertidumbre sobre la relación jurídica tributaria, que existe desde que se realizó el presupuesto normativo tributario, así se empleara una forma jurídica inadecuada, y en nada afecta que luego de declarar el abuso tributario, ese ropaje jurídico ficticio se desconozca, se recalifique el negocio y el resultado económico logrado se subsuma en el supuesto de hecho eludido.

Como esta decisión crea situaciones individuales o concretas es un acto administrativo definitivo, por tanto, es susceptible de impugnación judicial, previo agotamiento de la vía gubernativa mediante el recurso de reposición, según el art. 76 del CPACA. Asimismo como esta resolución se dicta antes de expedir las liquidaciones oficiales - aforo o revisión-, no se cuenta con las oportunidades para allegar pruebas (Estatuto Tributario, art. 744), por ende, el interesado podrá controvertir las aportadas o practicadas antes de que se dicte la decisión, de igual forma, debe dársele a conocer cualquier providencia que deniegue el decreto de determinada prueba.

No podemos desconocer que hay temas adicionales alrededor de este régimen que merecen un estudio exhaustivo por parte de otros investigadores, como lo es la incidencia que tendría la omisión de no haber incluido en esta norma, la suspensión de términos en el desarrollo de este juicio, así como evaluar la posibilidad que tiene el comité de delegar sus especiales funciones, al igual que establecer la solución que tendrían otros eventos elusivos que no encajan en los elementos de la CGA, entre otros. 


\section{Referencias}

Betti, E. (2010). Teoría general del negocio jurídico. Granada: Comares.

Cahn - Speyer Wells, P. (2016). La defraudación y la elusión fiscales: cláusulas antiabuso. En P. Cahn - Speyer Wells, Derecho crítico: perspectiva tributaria. Temis.

Cubides, J. (2005). Obligaciones. Bogotá: Pontificia Universidad Javeriana.

Devis, H. (2015). Teoría general de la prueba judicial. Tomo I. Bogotá: Temis.

Ferri, G. (1968). Causa e tipo nella teoria del negozio giuridico. Roma: Giuffrè.

González, E. (1997). La interpretación de las normas tributarias. Pamplona: Aranzadi.

Hensel, A. (2000). Derecho tributario. Rosario: Nova Tesis.

Hinestrosa, F. (1959). El negocio jurídico y la causa. Facultad de Derecho, 328.

Hoyos, C. (2006). La cláusula antielusiva en Colombia. Revista Latinoamericana de Derecho Tributario, (2)230.

Marín, G. (2009). La relevancia jurídica de la motivación fiscal. Madrid: Dykinson.

Marín, M. (2010).La estructura jurídica del tributo: el hecho generador. En J. R. Piza Rodríguez, Curso de derecho tributario, procedimiento y régimen sancionatorio. Bogotá: Universidad Externado de Colombia.

Muñoz, G., y Zornoza, J. (2015). La aplicación de las normas tributarias. En J. R. Piza Rodríguez, La obligación tributaria y sus fundamentos constitucionales. Bogotá: Universidad Externado de Colombia.

Narváez, J. (2008). Teoría general de las sociedades. Bogotá: Legis.

Ospina, G., y Ospina, E. (2000). Teoría general del contrato y del negocio jurídico. Bogotá: Temis.

Piza, J., y Castro, J. (2010). La aplicación de los tributos y el procedimiento de gestión. En J. R. Piza Rodríguez, J. J. Zornoza Pérez, G. Muñoz Martínez, M. Marín Elizalde, O. L. González Parra y M. C. Sánchez Peña (Eds.), Curso de derecho tributario, procedimiento y régimen sancionatorio. Bogotá: Universidad Externado de Colombia.

Ramírez,H. (2016). La aplicabilidad de la cláusula general anti-abuso en materia tributaria. Bogotá: Universidad del Rosario.

Ruiz, V., y Seitz, G. (2004). El fraude a la ley tributaria. Universidad Carlos III de Madrid. Madrid: Universidad Carlos III de Madrid. Recuperado de http://e-archivo.uc3m.es/bitstream/handle/10016/9761/fraude_ruiz_RCT_2004. pdf?sequence $=1$

Vargas, O. (2014). Derecho procesal administrativo modernización del Estado y territorio. Bogotá: Ibañez.

Whittingham, E. (2011). Las pruebas en el proceso tributario. Bogotá: Temis.

Zornosa, J., y Muñoz, G. (2010). Infracciones y sanciones tributarias. En J. R. Piza Rodríguez (Ed.), Curso de derecho administrativo, procedimiento y régimen sancionatorio. Bogotá: Universidad Externado de Colombia. 